\title{
The Status Quo Survey and Countermeasure Analysis of Chinese Netizens' Needs for E-Mental Health Services
}

\author{
Jian Zhao ${ }^{1}$ \\ ${ }^{1}$ School of Journalism and Communication, Southwest University, Chongqing, China \\ Correspondence: Jian Zhao, School of Journalism and Communication, Southwest University, Chongqing, China. \\ E-mail: zj74318@swu.edu.cn
}

Received: September 28, 2015

Accepted: November 10, 2015 Online Published: November 20, 2015

doi:10.5539/ass.v11n27p281

URL: http://dx.doi.org/10.5539/ass.v11n27p281

\begin{abstract}
The e-Mental Health Service refers to the work for mental health promotion provided, following the laws of mental health, by professional institutions and professionals to netizens through the Internet. A survey of 1588 netizens shows that netizens have a need for e-Mental Health Services and higher needs for mental health knowledge; they show obvious social orientation in their choices of service providers; demographic variables have remarkable influences on netizens' specific needs; and netizen groups, there are relatively higher needs in female, college degree holders and above, the youth and brain workers, such as students, teachers, company employees, and staff in public institutions. The results of the survey indicate that netizens' needs for e-Mental Health Services are complex and diversified, and netizens' understanding and demand for professional service institutions, professional service providers and electronic service modes still need to be improved.
\end{abstract}

Keywords: netizen, e-Mental Health Service, the needs for mental health service

\section{Instruction}

Referring to Huang Xiting's definition of mental health service system (Huang et al., 2007), the e-Mental Health Service, also known as the Internet-based Mental Health Services, can be defined as the work for mental health promotion provided, following the laws of mental health, by professional institutions and professionals to social members, especially netizens, through the Internet. Compared with traditional mental health services, the e-Mental Health Service, with unlimited service time and space, diversified service modes, shared resource, convenient information and large-scale services, could meet the need of China's 668 million netizens for mental health services theoretically (CNNIC, 2015). According to the definition given by China Internet Network Information Center (CNNIC), netizens refer to those Chinese residents aged 6 and above who have used the Internet in the past 6 months (CNNIC, 2015). And the first survey on netizens' health condition made at www.39.net in 2007 has revealed that $55.97 \%$ of 152,866 netizens had claimed to have, occasionally or frequently, mental problems (39.net, 2007). Therefore, it is necessary to provide netizens psychological guidance and assistance.

The e-Mental Health Service is an important channel for netizens to obtain mental health services, and the understanding of netizens' needs for the e-Mental Health Service is an essential basis on which electronic services could be carried out effectively. Yet up until now, it is unclear what the extent of Chinese netizens' needs for the e-Mental Health Service generally are and what characteristics the needs possess. The objects of existing studies have focused mainly on college students' needs for network services (Zhang, 2009; Wang et al., 2010; Cui et al., 2010). However, in the concept of promoting the construction of China's mental health service system, the study on netizens as a whole is of great significance. And as a vital component of the construction of China's mental health service system, it is conducive to clarifying Chinese netizens' needs for as well as their attitudes towards the e-Mental Health Service. Hence this study attempts to carry out exploratory work in this regard and put forward appropriate countermeasures.

\section{Survey}

\section{$2.1 \mathrm{Tool}$}

Following the specifications of psychometrics, the survey team has devised the Netizen's e-Mental Health Services Needs Questionnaire (NeMHSNQ). Referring to relevant domestic literature on the evaluation of the 
needs for mental health service, and on the basis of the series of scales developed by the research group of Research on the Actualities and Counter-measures of Mental Health Service in China, this survey, through open-ended questionnaires and interviews conducted in Chinese netizens, has concluded one dimension of acceptance attitude in which there are 8 items, and four dimensions of Chinese netizens' needs for e-Mental Health Services: service institution, service providers, service content and service mode, and in each dimension there are 7-8 alternative items, with 40 items in total. Then the survey team, along with psychology researchers, has reviewed the questionnaire, revised and pruned its items, and produced the preliminary questionnaire with 30 items at last. Moreover, referring to the format of the Likert Scale, the items in the questionnaire are ranked by five levels: in the dimension of needs, they are ranked as strongly unneeded, unneeded, a little needed, needed, and strongly needed; in the dimension of attitude, they are ranked as strongly unacceptable, unacceptable, a little acceptable, acceptable, and strongly acceptable.

\subsection{Investigator}

The survey team is consisted of 16 investigators distributed in 7 administrative districts in China, and all the investigator have respectively undergone special training in advance.

\subsection{Method}

Referring to the demographic proportion from the related statistical data of netizens published by CNNIC, the survey team has structuralized the samples to make it convenient for sampling.

\subsection{Sample}

In this survey, a total of 1653 questionnaires, of which 1588 questionnaires are valid, with a valid return rate of $96.07 \%$, have been collected from more than 20 cities and provinces, such as Beijing, Sichuan, Shandong, Anhui, Hubei, Hunan, Guangdong, Xinjiang, etc.

Table 1. Distribution of survey samples of Chinese netizens' needs for and attitudes to the e-Mental Health Service $(\mathrm{N}=1588)$

\begin{tabular}{|c|c|c|c|c|c|c|c|}
\hline \multicolumn{2}{|l|}{ Sex } & \multicolumn{2}{|c|}{ Age Group } & \multicolumn{2}{|l|}{ Educational Background } & \multicolumn{2}{|l|}{ Occupation } \\
\hline Male & 749 & $<20$ & 183 & College degree and above & 1340 & Student & 563 \\
\hline Female & 836 & $20-29$ & 1162 & Others & 246 & Teacher & 164 \\
\hline \multirow[t]{8}{*}{ Missing } & 3 & $30-39$ & 159 & Missing & 2 & Worker & 81 \\
\hline & & $40-49$ & 62 & & & Company employee & 353 \\
\hline & & $50 \geq$ & 20 & & & Freelance & 95 \\
\hline & & Missing & 2 & & & Staff in public institutions & 212 \\
\hline & & & & & & Unemployed/Laid-off & 60 \\
\hline & & & & & & $\begin{array}{l}\text { Worker in farming, forestry, } \\
\text { animal husbandry and fishery }\end{array}$ & 42 \\
\hline & & & & & & Others & 13 \\
\hline & & & & & & Missing & 5 \\
\hline
\end{tabular}

Note: Occupation classification refers to demographic data in CNNIC's survey report.

\section{Result and Analysis}

\subsection{Service Institution}

Netizens sort the institutions that provide e-Mental Health Services in descending order: "psychological center in schools" (2.98 \pm 1.02$)$, "mental health services" $(2.81 \pm 0.99)$, "psychiatry or psychological department in hospitals" (2.80 \pm 1.06$)$, "departments of epidemic prevention and health care" (2.78 \pm 0.97$)$, and "private psychological institution" $(2.74 \pm 0.98)$, indicating that for netizens the most recognized one is "psychological center in schools", then is other public service institutions, and the last is private service institutions.

Specifically speaking, "psychological center in schools" is the first choice in all sex groups, under 40 age groups, college degree holders and above, students, teachers, company employees and freelances; "departments of epidemic prevention and health care" is the first choice in above 40 age groups and workers in farming, forestry, 
animal husbandry and fishery; and "mental health services" is the first choice of workers and the unemployed/laid-off. Moreover, netizens' second choices are also different: under 30 age groups and above 40 age groups, students, teachers and freelances choose "mental health services"; 30-39 age group and company employees choose "psychiatry or psychological department in hospitals"; the unemployed/laid-off choose "departments of epidemic prevention and health care"; the educational background group with lower degree than college degree and workers in farming, forestry, animal husbandry and fishery choose "psychological center in schools". In the end, "private psychological institution" is the last choice of netizens when they need e-Mental Health Services.

\subsection{Service Content}

In general, the rank order of netizens' needs for service content (from high to low) is "personal development" (3.38 \pm 0.98$)$, "self-management" (3.27 \pm 0.94$)$, "interpersonal relationship" (3.26 \pm 0.92$)$, "love and marriage" $(3.22 \pm 0.95)$, and "children education" $(3.14 \pm 1.00)$, indicating that generally Chinese netizens' primary concern is promising personal development followed by effective self-management.

More specifically, firstly, "personal development" is the most desired service content in all sex groups, all educational background groups, under 30 age groups, students, and freelances; "children education" is the most desired in above 30 age groups, teachers, workers, staff in public institutions, and workers in farming, forestry, animal husbandry and fishery; and "self-management" is the most desired for company employees and the unemployed/laid-off. Secondly, the female group, college degree holders and above, below 20 age group and above 30 age group, company employees, the unemployed/laid-off, staff in public institutions, and workers in farming, forestry, animal husbandry and fishery focus more on "self-management", while the male group, 20-29 age group, educational background group with lower degree than college degree, students, and freelances focus more on "interpersonal relationship". Finally, "children education" is the least desired service content in all sex groups, all educational background groups, under 30 age groups, students and company employees; "love and marriage" is the least in 30-39 age group and above 50 age group, workers, freelances, the unemployed/laid-off, and workers in farming, forestry, animal husbandry and fishery; and "interpersonal relationship" is the least in 40-49 age group, teachers and staff in public institutions.

\subsection{Service Mode}

In general, the rank order of netizens' needs for service modes (from high to low) is "counseling through typing on communication software" ( $3.02 \pm 0.95$, hereafter referred to as "typing counseling"), "email counseling" (2.94 \pm 0.90$)$, "phonetic counseling on communication software" $(2.92 \pm 0.93$, hereafter referred to as "phonetic counseling"), "counseling through webpage online massage" (2.89 \pm 0.93 , hereafter referred to as "webpage counseling"), and "video counseling on communication software" (2.65 \pm 0.97 , hereafter referred to as "video counseling"), showing that netizens might prefer counseling modes which could better hide themselves.

Specifically speaking, "typing counseling" is the most desired mode in all sex groups and educational background groups, under 50 age groups, neitzens with different occupational groups (except for workers in farming, forestry, animal husbandry and fishery); "webpage counseling" is the most desired mode for netizens aged above 50; and "email counseling" is the most desired for workers in farming, forestry, animal husbandry and fishery. As for the second choice of service mode, the female group, 20-29 age group and above 50 age group, college degree holders and above, students, workers, company employees and the unemployed/laid-off choose "email counseling"; the male group, under 20 age group and 30-39 age group, educational background group with lower degree than college degree, teachers, and freelances choose "phonetic counseling"; and 40-49 age group and workers in farming, forestry, animal husbandry and fishery choose "webpage counseling". Besides, netizens' needs for "video counseling" are the least.

\subsection{Service Provider}

Netizens' needs for service providers include that for professional and non-professional service providers. Overall, with regard to netizens' needs for professional service providers, the rank order (from high to low) is "psychological counselor" ( $3.11 \pm 0.96)$, "psychological counseling teacher" $(3.00 \pm 0.98)$, and "psychiatrist or psychologist" $(2.82 \pm 1.02)$. As for the needs for non-professional service providers, netizens' needs for "classmates and friends"( $3.46 \pm 0.91)$ and "family members"(3.32 \pm 0.99$)$ have obtained relatively higher rank.

More specifically, netizens' needs for non-professional service providers are higher than that for professional service providers in all sex groups, all age groups, and all educational background groups. The differences lie in that above 40 age groups regard "family members" as the first choice, while other age groups choose "classmates and friends" first; and in occupational groups, workers prefer "family members", while other 
occupational groups prefer "classmates and friends". In terms of the needs for professional service providers, all sex groups and all educational background groups make "psychological counselor" their first choice and "psychological counseling teacher" the second; under 20 age group and above 50 age group choose "psychological counseling teacher" first, while 20-49 age groups choose "psychological counselor" first; in occupational groups, teachers make "psychological counseling teacher" first, while all the other groups make "psychological counselor" first. Besides, "psychiatrist or psychologist" is the least desired choice in all sex groups, all educational background groups, and all occupational groups.

\subsection{Acceptance Attitude}

In the dimension of acceptance attitude, netizens' acceptance ranks from high to low: "to learn mental health knowledge through the network" ( $3.13 \pm 0.92)$, "to do psychological test through the network" $(3.09 \pm 0.96)$, "to receive mental health education through the network" $(2.96 \pm 0.93)$, "to do psychological counseling through the network" $(2.96 \pm 0.97)$, and "to receive psychotherapy through the network" $(2.69 \pm 0.95)$, indicating that there is a certain acceptance of various network services in netizens, but not much. "To learn mental health knowledge through the network" and "to do psychological test through the network" are of the highest acceptance in all sex groups, all educational background groups, all occupational groups, and under 50 age group, while "to receive psychotherapy through the network" is of the lowest. And netizens aged 50 and above are most willing to "learn mental health knowledge" and "receive mental health education" through the network, while most unwilling to "to do psychological counseling" through the network.

\section{Countermeasure and Suggestion}

Based on the analysis of the results of this survey, we put forward following suggestions and countermeasures for e-Mental Health Services:

\subsection{Improving Chinese Netizens' Acceptance ATtitude toward E-Mental Health Services through Popular Science Education}

According to the frequency statistics on the five sub-items of acceptance attitude, the positive acceptors, who choose "acceptable" or "strongly acceptable", account for 35.2\% in "learning mental health knowledge", $27.7 \%$ in "receiving mental health education", $28.8 \%$ in "receiving psychological counseling", $34.8 \%$ in "receiving psychological test", and 19.3\% in "receiving psychotherapy". And if counting in potential acceptors who choose "a little acceptable", the proportion of acceptors will climb to $76.6 \% 、 68.6 \% 、 68 \% 、 72.6 \%$ 和 $55.7 \%$ respectively. In light of this consideration, there is a need in taking advantage of all available channels to propagandize potential adopters in netizens on mental health knowledge and psychological science, so as to raise their awareness on e-Mental Health Services, turn potential acceptors into positive acceptors, and further lead to a wider use in the e-Mental Health Service. In fact, among the occupational groups, teachers' score is generally higher than other occupations, which fully demonstrates the importance of public education. Teachers get higher scores in all dimensions of needs and their sub-items, among which their needs for professional service providers and service mode are significantly higher than other occupational groups. The reason might lie in two aspects: one is that teachers generally have a better understanding and use of the Internet, which makes them easier to accept electronic services; the other is teachers have received psychology education, so they have a better understanding and acceptance for professional service providers. Therefore, in promoting the development of e-Mental Health Services, netizens' acceptance might be significantly improved through relevant education and guidance.

4.2 Striving to Improve the Service Level of Public Mental Health Services, Like "Psychological Center in Schools", and Expand the Scope of Service

According to the results of this survey, Chinese netizens have more needs for public mental health services, such as "psychological center in schools", "mental health institute", and "departments of epidemic prevention and health care", while a relatively lower need for "private psychological institution". But among 202 active mental health website in this survey, private institutions accounts for $90.2 \%$, psychological institutions in schools only account for $7.4 \%$, medical institutions only $1.5 \%$, and other kind of institutions $1 \%$, showing that there are some contradictions between the reality and netizens' needs, and public institutions needed by more netizens, especially "psychological center in schools", fail to give full play to their functions in e-Mental Health Services. In 2013, a survey of 1553 university websites was conducted in the mainland china, finding that only $50.9 \%$ of those websites had been providing e-Mental Health Services, most of which are non-independent sites, with a popularizing rate far below $97.9 \%$ of university websites in Taiwan (Wu \& Yan, 2008). What's more, most of e-Mental Health Services provided by mainland universities are quite imperfect, with limited service content of providing students popular science and service information and out of bounds for outsiders. Hence, public health 
service institutions should improve their e-service mechanism, enrich their service content, extend their coverage in netizens, and meet netizens' needs for e-Mental Health Services.

4.3 Intensifying the Publicity of the Functions of Professional Service Providers and Establishing Interpersonal Support System in Society

In the needs for professional service providers, "psychological counselor" has a higher degree of approval in netizens than "psychiatrist", indicating that the title of "psychological counselor" has been recognized in society over the years. And mental health services and psychiatry departments or psychological department in hospitals should strengthen the propaganda in society and undertake more public-spirited activity, so as to popularize mental health knowledge and improve netizens' understanding and acceptance for psychiatrists. Moreover, since netizens still have greater dependence on nonprofessional service providers and many studies have revealed that Chinese netizens have a characteristic of social orientation in the choice of e-Mental Health Services (Huang et al., 2007; Luo, 2010), it is necessary to intensify the publicity of the functions of professional service providers, so as to let netizens know that, confronted with mental problems they should turn to professional service providers who could maintain and promote their mental health in many respects.

\subsection{Showing Respect for the Concept of Privacy for the Chinese and Gradually Evolving Service Modes}

This survey reveals that, as for the service modes, netizens prefer the non-video modes. The most criticized deficiency of Internet-based psychological consulting is the lack of non-verbal information support during the counseling, which makes counselors difficult to learn the real situation of their clients (Hsiung, 2001). Therefore most psychological counselors advocate audio/video counseling as a substitute mode of face-to-face counseling. However, perhaps due to the Oriental concept of privacy the mode of audio/video counseling has a relatively low degree of approval in netizens. The survey shows that $65.9 \%$ of netizens hope to counsel anonymously, $6.5 \%$ take no account of anonymity; $42.1 \%$ of netizens are worried about online psychological counselors' leaking information, $12.3 \%$ take no account of this issue; $21.3 \%$ of netizens regard online mental health institutions as trustable, $15.8 \%$ regard them as un-trustable. This problem could be solved from three aspects: one is to intensify the publicity and guidance for the public to eliminate the misunderstanding of psychological counseling; another one is to provide netizens various modes of counseling to allow them to find the most effective mode gradually by themselves; the third one is to strengthen the regulation of online mental health counseling, improve professional quality of online counselors, so as to establish a positive image for winning netizens' recognition.

\subsection{Taking Fully into Account of the Differences in Needs to Provide More Pertinent and Targeted E-Services}

The significant differences in demographic variables of Chinese netizen' various needs for services have provided an important basis for more pertinent and targeted e-services. It is worth mentioning here that the difference between the e-service and traditional services is the e-service could provide a certain amount of intellectualized services. For example, the e-service can provide mental health hospitalization guidance services, Information Push Services, Frequently Asked Questions, and other kind of services based on netizens' gender, age, educational background, and occupation. Moreover, the e-service is conducive to the management and sharing of online clients' data. And the basis of these intellectualized services and management lies in the significant differences in demographic variables.

4.6 Paying Attention to the Mental Health of Netizen Groups as the Unemployed/Laid-Off, Workers in Farming, Forestry, Animal Husbandry and Fishery, etc. and Taking the Service Strategy of Positive Intervention to Raise Their Awareness of Mental Health

It has been showed in some survey that there is a lack of the service awareness of mental health in migrant workers (Li et al., 2011), and the results of this survey also back that conclusion. Meanwhile, this survey reveals that the unemployed/laid-off netizens lack the service awareness of mental health as well. Hence it is recommended that for groups lacking mental health awareness subjectively compulsory counseling and assistance should be given in accordance with external intervention strategy.

\section{Acknowledgements}

The Fundamental Research Funds for the Central Universities (Southwest University), project number: SWU 1009006. "Research on Web Based Public Mental Health Service in China".

\section{References}

39.Net. (2007). White Paper on Chinese Netizens' Health Condition. Retrieved from http://dc.39.net/079/14/126620.html.

China Internet Network Information Center. (2015). The $36^{\text {st }}$ Statistical Report on Internet Development in 
China. China Internet Network Information Center. Retrieved from http://www.cnnic.cn/gywm/xwzX/rdxw/2015/201507/t20150723_52626.htm

Cui, L. X., Lei, L., \& Liu, Y. N. (2010). A Comparative Study of College Students' Attitude toward Network and Face-to-Face Counseling. Psychological Development and Education, (1), 81-86.

Hsiung, R. C. (2001). Suggested Principles of Professional Ethics for the Online Provision of Mental Health Services. Studies in Health Technology and Informatics, 84(2), 296-300.

Huang, X. T., Zheng, Y., Bi, Z. Z, \& Chen, Y. Z. (2007). Problems about the Construction of the Mental Health Service System in China. Psychological Science, 30(1), 2-5.

Li, Q, Yin, T. Z., Yang, S., \& Wang, X. G. (2011). Investigation and Countermeasures of the Mental Health Service Needs of Migrant Workers. Journal of Southwest University (Social Science Edition), 37(3), 12-16.

Luo, M. C. (2010). The Present Status of Mental Health Service Needs in Chinese Youth and Teenage (Unpublished doctoral dissertation). Southwest University, Chongqing, China.

Wang, H., Zhao, X., \& Zhou, J. (2010). On Needs and Attitudes of Online Mental Health Education for Undergraduate Students. Journal of Architectural Education in Institutions of Higher Learning, 19(3), $152-155$.

Wu, N. N., \& Yan, Y. W. (2008). The Present Situation and Enlightenment of e-Mental Health Education in Colleges and Universities in Taiwan, China. Education Exploration, (1), 117-118.

Zhang, Y. H. (2009). Investigation and Analysis of College Students' Cognition and Application of Internet Psychological Counseling. Modern Education Science, (2), 114-116.

\section{Copyrights}

Copyright for this article is retained by the author(s), with first publication rights granted to the journal.

This is an open-access article distributed under the terms and conditions of the Creative Commons Attribution license (http://creativecommons.org/licenses/by/3.0/) 